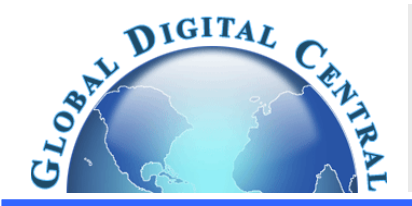

\title{
EXPERIMENTAL INVESTIGATION OF A LIQUID COOLING SYSTEM FOR A THERMOELECTRIC POWER GENERATOR SYSTEM USING ETHYLENE GLYCOL AS A NEW COOLANT
}

\author{
Weera Punin, ${ }^{*}$ Somchai Maneewan, Chantana Punlek \\ Research and Energy Management Center, Department of Physics, Faculty of Science, \\ Naresuan University, Phitsanulok, 65000, Thailand
}

\begin{abstract}
In the present experimental investigation, ethylene glycol cooling in a plate-fin heat sink was attached inside an aluminum cooling block for the cooling unit of a thermoelectric (TE) power generator system. The plate-fin heat sink with two different fin heights was made from aluminum with length, width and base thickness of 300, 200, and $25 \mathrm{~mm}$, respectively. The ethylene glycol was used as a coolant. The effects of fin height, coolant volume flow rate, and hot side surface temperature were considered for the temperature differences between the hot side surface and cold side surface of the TE power module. The ethylene glycol cooling of the rectangular plate-fin heat sink inside the aluminum cooling block was compared to water and air cooling. The plate-fin heat sink for ethylene glycol cooling showed a significant effect on the cold side surface of the TE power module for cooling of the TE power generator system. The experiments were performed under conditions of the heat input to the hot side surface area within 60 min after steady state, for which the volumetric flow rates were $0.005,0.010$ and $0.015 \mathrm{~m}^{3} / \mathrm{min}$. The results indicated heat transfer rate increase with increasing coolant volume flow rate and higher fin. When compared to the water and air cooling methods, the plate-fin is attached inside the aluminum cooling block gives the highest efficiency. The results of this study could be used for guidance that will enable the design of a cooling system with improved heat transfer performance in a TE power generator system.
\end{abstract}

Keywords: Thermoelectric power generators; A liquid cooling system; Ethylene glycol coolant; Plate-fin heat sink

\section{INTRODUCTION}

Due to increasing demand for higher performance from TE generators under temperature control on the cold side surface of the TE power module and level reliability of heat rejection, improvements will have required for these devices. The development of a new cooling technology for physical performance has rapidly increased, especially in electronic engineering and other related fields. Over the past several years, various articles and reports have been presented evaluating the performance of TE power generators. Rowe and Min (1996) found an increase in the conversion efficiency of a TE module by employing a lower heat transfer rate through the module. Zhao and $\mathrm{Lu}$ (2002) presented an analytical and numerical study on the heat transfer characteristics of forced convection across a microchannel heat sink. Cheng and Lin (2005) proposed a method for using a genetic algorithm to maximize cooling capacity and found that optimizing the dimensions of the TE cooling module could increase its cooling capacity. Yang et al. (2005) studied the transient response of TE coolers with and without mass loads through examination of both the minimum temperature reached and the time constants involved in the cooling and the recovering stages. In the same year, Peles et al. (2005) investigated heat transfer and pressure drop phenomena over a bank of micro pin fins. It was found that those very low thermal resistances are achievable using a pin fin heat sink. The thermal resistance values are comparable with the data obtained in microchannel convective flows. Siu-Ho et al. (2006) measured pressure drop and temperature distribution of a singlephase micro-pin-fin heat sink for evaluating average friction factor and local averaged heat transfer coefficient/Nusselt number. Kim et al. (2008) compared the thermal performances of the two types of heat sinks most commonly used in the electronic equipment cooling: platefin and pin-fin heat sinks. The results showed that plate-fin heat sinks possess lower thermal resistances than optimized pin-fin heat sinks when dimensionless pumping power is small and the dimensionless length of heat sinks is large. On the contrary, the optimized pin-fin heat sinks have smaller thermal resistances when dimensionless pumping power is large and the dimensionless length of heat sinks is small.

Whelan and Robinson (2009) investigated the cooling capabilities of impinging water jet arrays. It was found that the confined-submerged tests yield greater heat transfer coefficients compared with their free jet counterparts. Hsiao et al. (2010) developed of thermoelectric generators and a cooling system for improving the efficiency of an IC engine. Two potential positions on an automobile chosen to apply this module e.g. exhaust pipe and radiator to check the feasibility. The results showed that the better efficiency of the thermoelectric module on the exhaust than on the radiator. Champier et al. (2011) presented a prototype thermoelectric generator for a fire stove. It found that the performing of the generator mostly depends on the heat transfer through the modules and especially on the thermal contact resistance. Pang et al. (2012) investigated the cooling system of an internal combustion engine by coupling one-dimensional and three-dimensional simulations. The results of the study showed that the thermal performance of the radiator played a critical role in cooling system performance. Wang et al. (2012) developed three-dimensional numerical model of TEs. It was found that the properties and the heat losses have significant effects on the TEC performance. After that, Mehrtash et al. (2013) studied the effect of

\footnotetext{
*Corresponding author. Email: verapunin@hotmail.com
} 
inclination on a plate-fin heat sink on heat dissipation by numerical simulation with three-dimensional steady-state natural convection. Rubio-Jimenez et al. (2013) compared of the performances of online and offset micro pin-fin heat sinks with variable fin densities. The results indicated that the offset micro pin-fin heat sink is a good alternative for cooling the IC chips of 2016. Jang et al. (2013) investigated the effects of flue gas temperature and flue gas speed on a 3-D numerical model of a TEG module with plate-fin used in a waste heat recovery system. In the same year, Fan et al. (2013) studied a cylindrical oblique fin minichannel heat sink to fit over cylindrical heat sources in the form of an enveloping jacket. it was found that the averaged Nusselt number, Nuave for the cylindrical oblique-cut fin minichannel heat sink increases up to $75.6 \%$ and the total thermal resistance decreases up to $59.1 \%$ when compared with the conventional straight fin minichannel heat sink. Favrel et al. (2014) investigated the electric power extractable from a system equipped with thermoelectric modules and limits on electricity generation the influence. It was found that each thermoelectric fabrication there is an ideal occupancy rate which can vary greatly. Prajapati et al. (2015) investigated channel configurations are uniform cross-section, diverging cross-section and segmented finned microchannels. It was found that performs of diverging cross-section channels is better than the uniform cross-section channels.

In this paper, the main objective is to study the heat transfer characteristics of an aluminum cooling plate-fin heat sink block for TE power generator systems. The effects of relevant parameters for ethylene glycol cooling on the cold side of the TE power module were considered.

\section{EXPERIMENTAL SETUP}

The experimental setup for generation of the performance test for the TE power modules is shown in Fig. 1. The test device consists of an electric heater, a TE power module, an ethylene glycol cooling system and a data acquisition system. The closed loop ethylene glycol cooling system consists of a storage tank, fluid pump, flow meter, and radiator. The test section and connections of the ethylene glycol cooling system were designed such that the parts could be assembled easily or repaired easily. The researchers selected TE power modules of TEG1-127-4040-250 for the experiment because they are commercially available TE modules at low cost, as shown in Table 1 below. The TE power modules were clamped between the aluminum cooling block and the electric heater $(2,700 \mathrm{~W}$ at $20 \mathrm{~cm} \mathrm{x} 40 \mathrm{~cm})$. The electric heater was made of stainless steel. The resistance ribbons were wound on a mica sheet to provide the heat source, which was proportional to the applied voltage. The electric heating comprised a plate-type heat exchanger with ethylene glycol coolant flowing through the interior multi fin of the aluminum cooling block to control the cold-end temperature of the TE power module. The ethylene glycol coolant flows through these multi fin, absorbing excess heat from the cold side surface of the TE power module, after which it exits the aluminum cooling block on its way to the radiator. At the radiator, the ethylene glycol coolant is pushed through a network of even narrower channels, which are cooled by having air blown over them by a fan. After that, the ethylene glycol coolant then flows back to the reservoir and begins its journey again. The volumetric flow rate of the ethylene glycol coolant is controlled by adjusting the valve and measuring with a flow meter. The test sections fabricated from the aluminum cooling block with the details are listed in Table 2. The temperatures measured for ethylene glycol cooling at various positions are shown in Fig. 1.

The plate-fin heat sink is presented in Fig. 2. This experiment was conducted with various ethylene glycol coolant flow rates, fin heights for the plate-fin heat sink, and temperatures on the hot side surface of the TE power module. The hot side surface temperature of the TE power module was adjusted to achieve the desired result by setting the run condition of the electric heater.

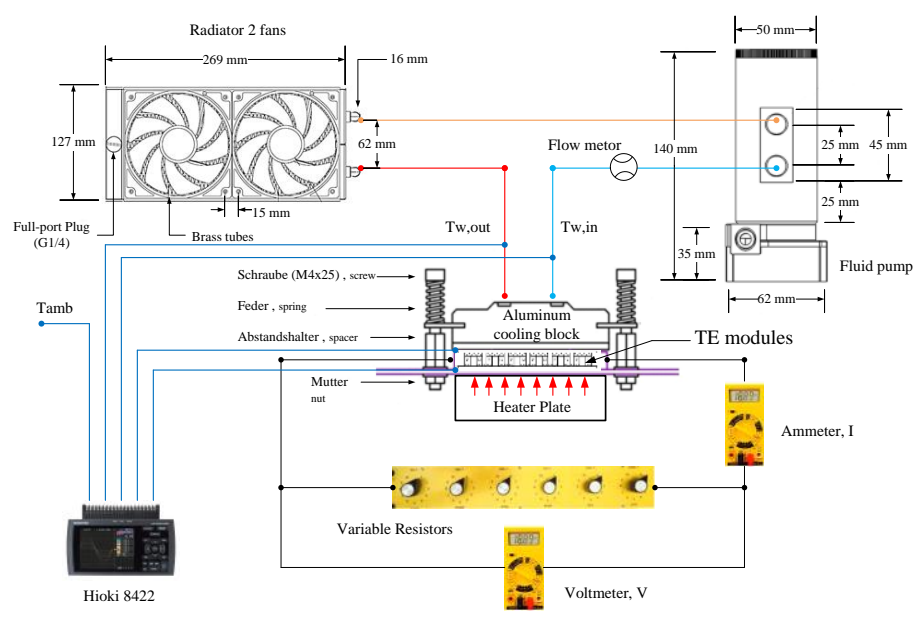

Fig. 1 Schematic diagram of the experimental apparatus

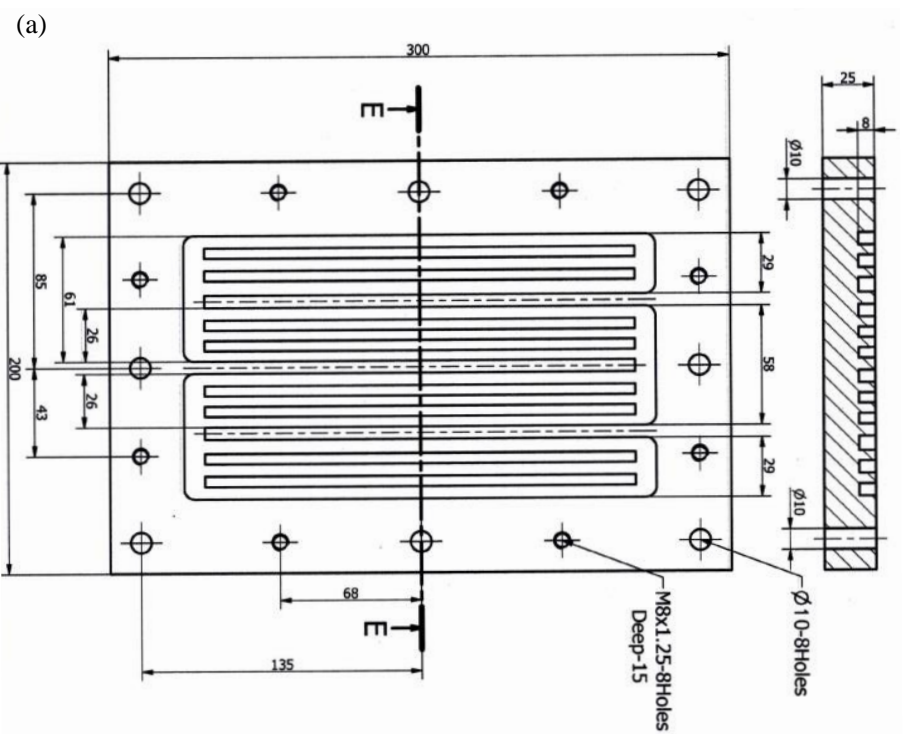

(a) Schematic diagram of plate-fin heat sinks

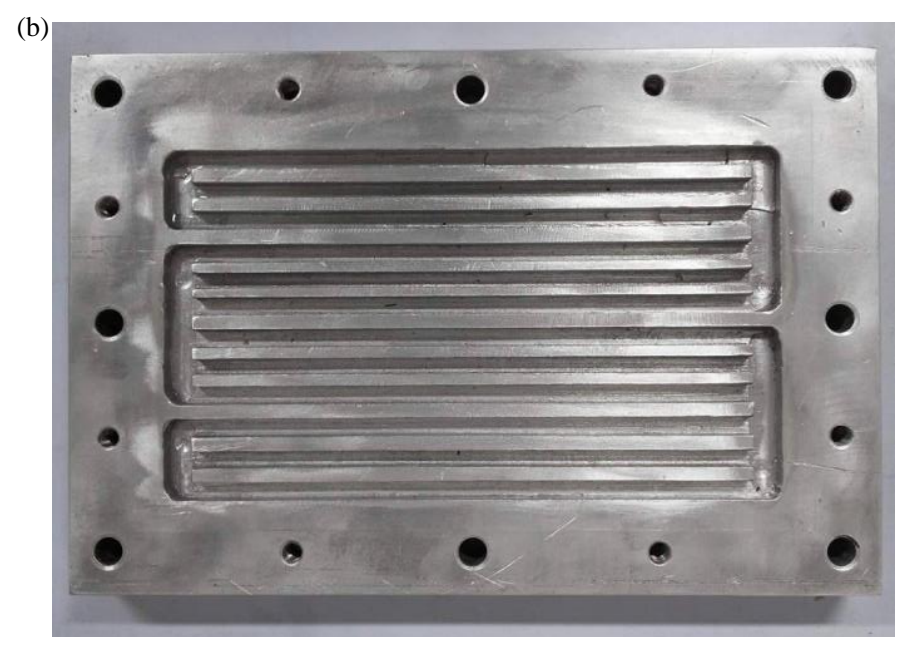

(b) Photograph of the aluminum plate-fin heat sinks

Fig. 2 The aluminum plate-fin heat sinks components, including (a) schematic diagram of plate-fin heat sinks, and (b) photograph of the aluminum plate-fin heat sinks 
Table 1. Characteristics of some commercially available thermoelectric

\begin{tabular}{|l|c|}
\hline \multicolumn{1}{|c|}{ Parameters } & TEG1-127-40-40-250 \\
\hline TE module sizes $(\mathrm{mm})$ & $40 \times 40 \times 3.7$ \\
\hline Max. Operating hot-side temp. $\left({ }^{\circ} \mathrm{C}\right)$ & 250 \\
\hline Max. output power $(\mathrm{W})$ & 7.8 \\
\hline Max. output current $(\mathrm{A})$ & 1.5 \\
\hline Max. output voltage (V) & 10.4 \\
\hline No. of couples & 127 \\
\hline Module cost (US\$) & 12 \\
\hline
\end{tabular}

Table 2 Dimensions of the plate-fin heat sinks

\begin{tabular}{|c|c|c|c|c|}
\hline Channel & $\begin{array}{c}\text { Size of the } \\
\text { cooling block } \\
(\mathrm{mm})\end{array}$ & $\begin{array}{c}\text { Plate-fin } \\
\text { height } \\
(\mathrm{mm})\end{array}$ & $\begin{array}{c}\text { Plate-fin } \\
\text { thickness } \\
(\mathrm{mm})\end{array}$ & $\begin{array}{c}\text { Channel } \\
\text { width } \\
(\mathrm{mm})\end{array}$ \\
\hline Aluminum & $300 \times 200 \times 25$ & 8 & 5 & 6 \\
\hline Aluminum & $300 \times 200 \times 25$ & 5 & 5 & 6 \\
\hline
\end{tabular}

\section{RESULTS AND DISCUSSION}

In this experiment, the cold side surface of a TE power module was attached to the surface of an aluminum cooling block, while the hot side surface of a TE power module was attached to the surface of a heat source by an aluminum heat exchanger. Investigations were carried out by controlling the temperature on the hot side surface of the TE power module at 100,150 and $200{ }^{\circ} \mathrm{C}$. Thermoelectric generator efficiency measurements require quantifying the heat input temperatures to the hot side surface and the heat removed from the cold side surface and then removed to the plate-fin heat sink. Effects of a fin height on the platefin heat sink in terms of the temperature difference between the hot side surface and cold side surface of the TE power module for different temperature conditions are shown in Fig. 3. Due to the higher heat transfer area, the heat transfer rate from the hot side surface of the TE power module to the cold side surface and plate-fin heat sink increases. Therefore, the temperature difference between the hot side surface and cold side surface of the TE power module obtained from the plate-fin heat sink with a fin height of $8 \mathrm{~mm}$ was higher than that obtained with a fin height of $5 \mathrm{~mm}$, especially for the hot side surface temperature at $200{ }^{\circ} \mathrm{C}$. It can be seen from the figure that the temperature difference between the hot side surface and cold side surface of the TE power module for the hot side surface temperature at $200{ }^{\circ} \mathrm{C}$ (the fin height of $8 \mathrm{~mm}$ ) is higher than the other temperature for the entire range of the period time, as shown in Fig. 4. Effects of the ethylene glycol coolant flow rate on the temperature difference between the hot side surface and cold side surface of the TE power module under the hot side surface temperature different conditions are shown in Fig. 5. For the three different coolant flow rates, a large temperature difference between the hot side surface and cold side surface of the TE power module is found for a larger coolant flow rate. The larger the temperature difference between the hot side surface and cold side surface of the TE power module, the more electrical current is produced and more power generated as a result.

The temperature difference between the hot side surface and cold side surface of the TE power module obtained from the ethylene glycol coolant cooling for the plate-fin heat sink on the cold side surface of the TE power module was compared to water and air cooling methods, as shown in Fig. 6. It can be seen that an aluminum cold plate-fin heat sink with ethylene glycol coolant has a significant effect on the cooling of the TE power generator system. The power output of the TE power module obtained from the ethylene glycol cooling was compared to water and air cooling methods show that Fig. 7. It was found that the power output of the TE power module was about $8.9 \mathrm{~W}$ per module, which is higher than that of water cooling and air cooling. The relative error $(\%)$ for all the power output of the TE power module analyzed was less than $0.072 \%$.
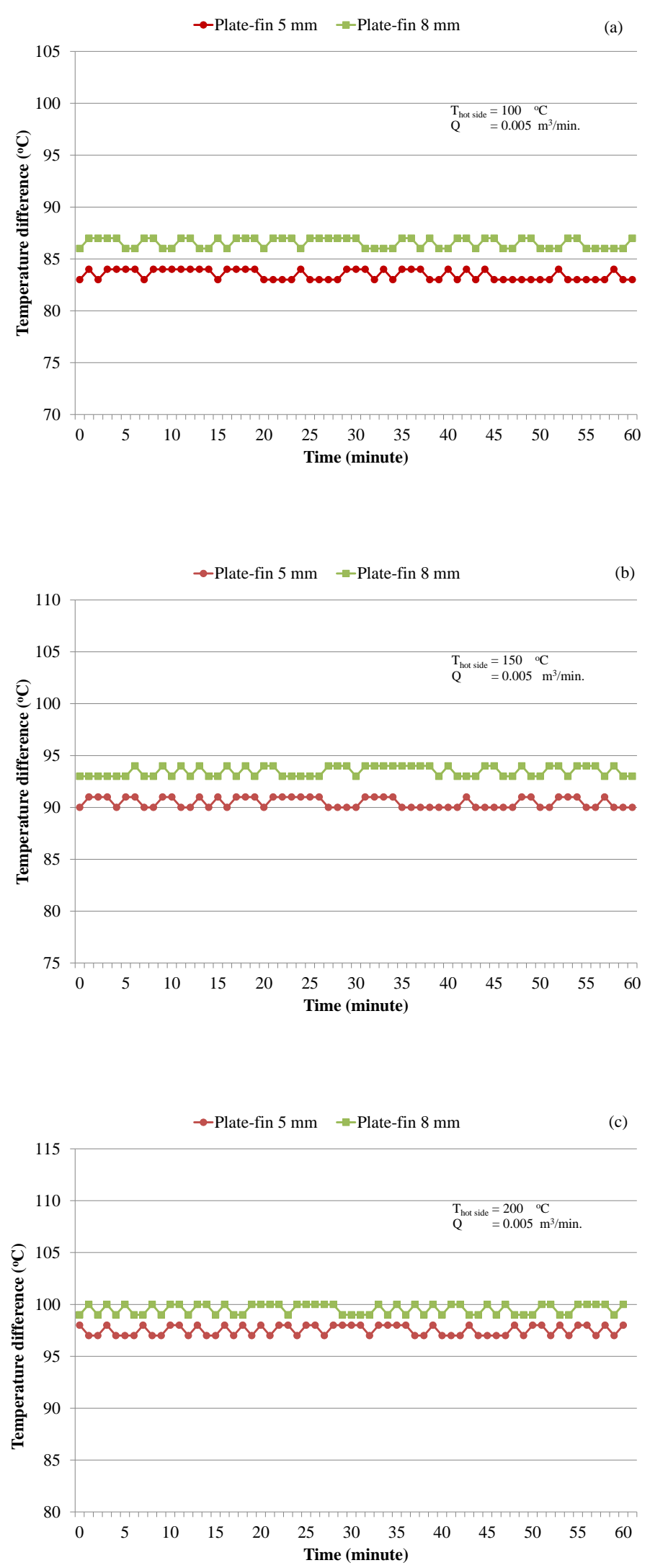

Fig. 3 Effects of fin height on the temperature difference between the hot and cold sides of a TE power module for (a) hot side temperature of $100{ }^{\circ} \mathrm{C}$, (b) hot side temperature of $150{ }^{\circ} \mathrm{C}$, and (c) hot side temperature of $200{ }^{\circ} \mathrm{C}$ 


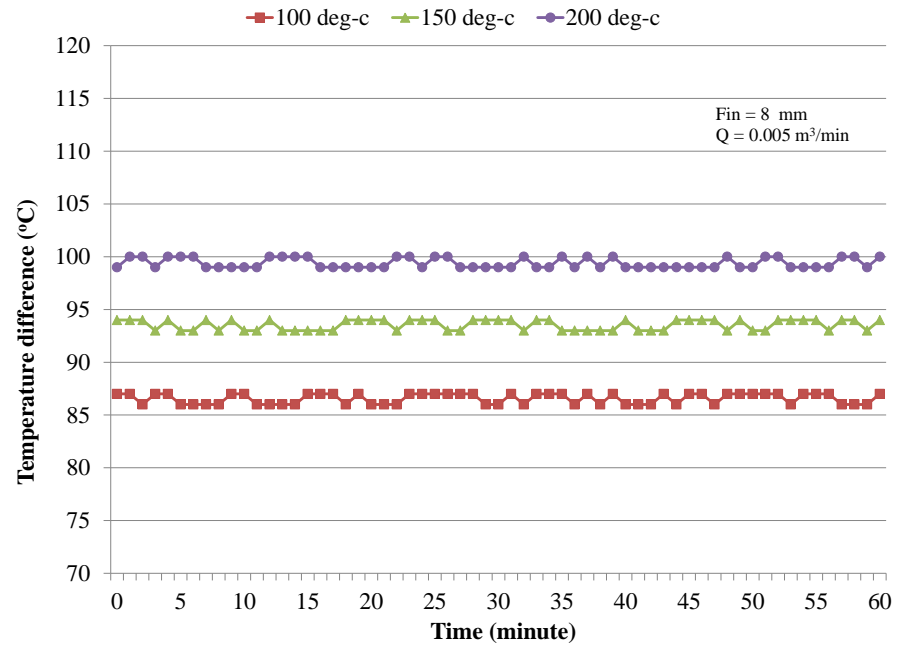

Fig. 4 Variations of the temperature difference between the hot and cold sides of a TE power module with time for the hot side of the TE power module under different conditions
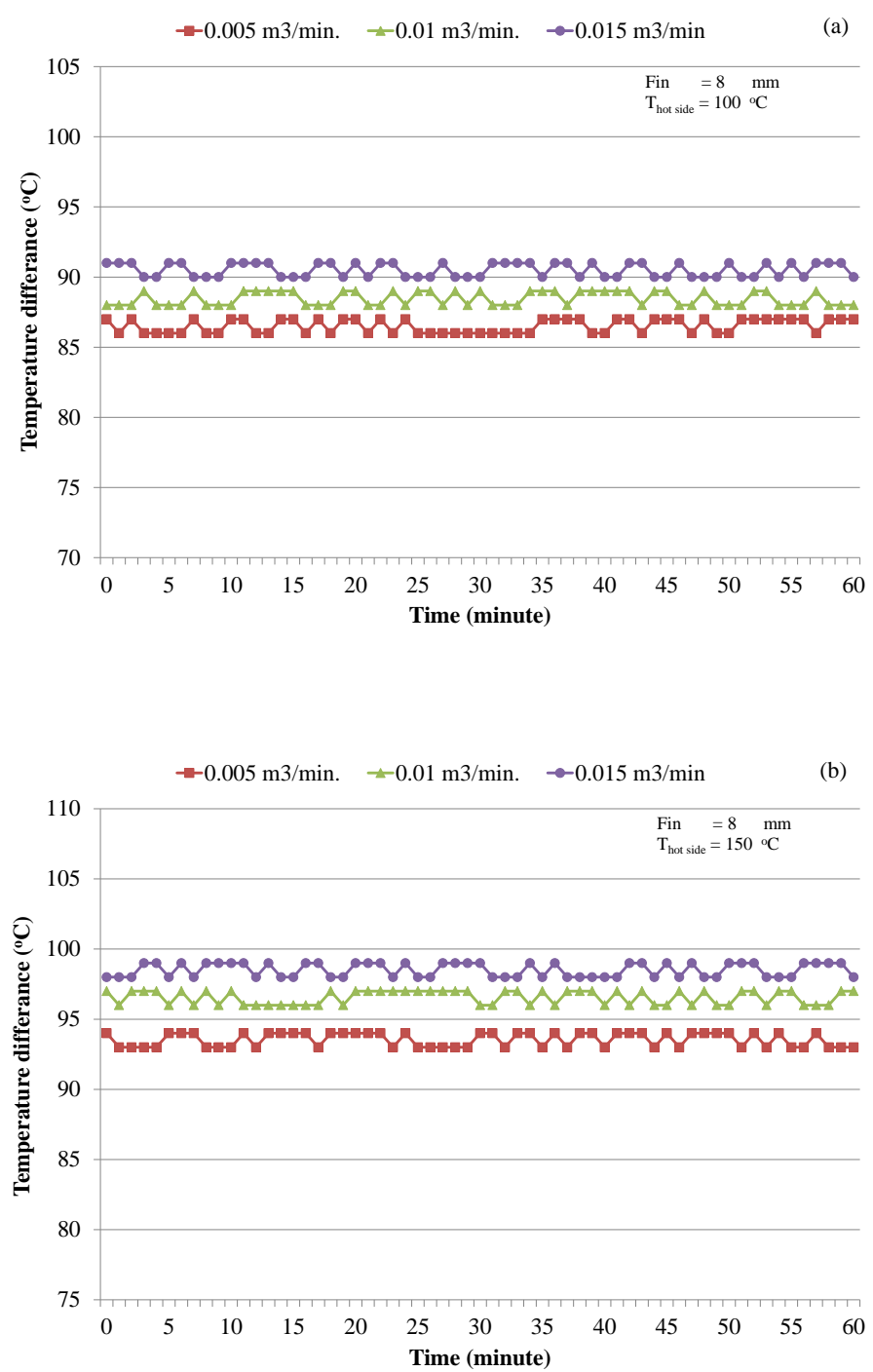

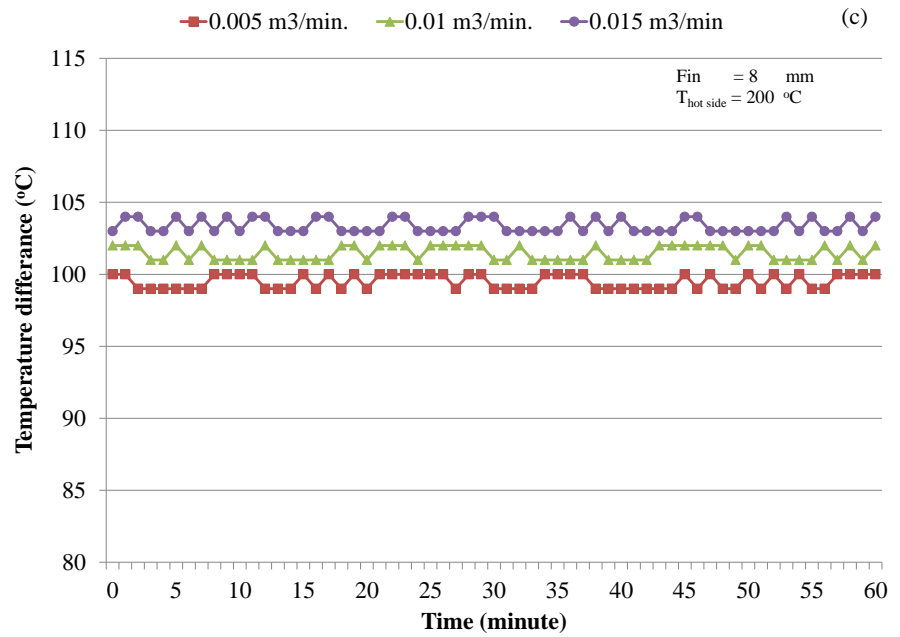

Fig. 5 Effects of coolant flow rate on the temperature difference between the hot and cold sides of a TE power module for (c) hot side temperature of $200{ }^{\circ} \mathrm{C}$

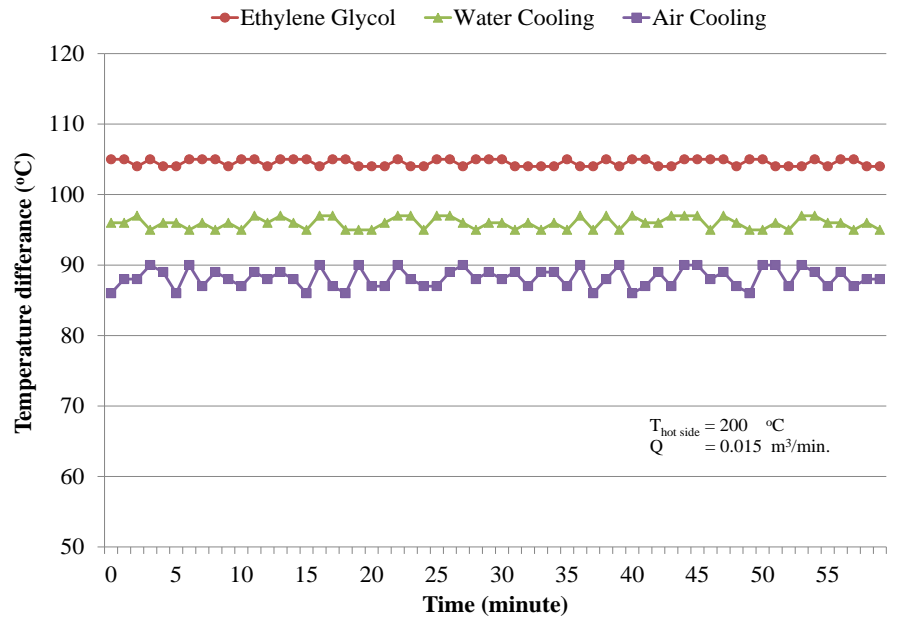

Fig. 6 Effects of cooling technique on the temperature difference between the hot and cold sides of a TE power module

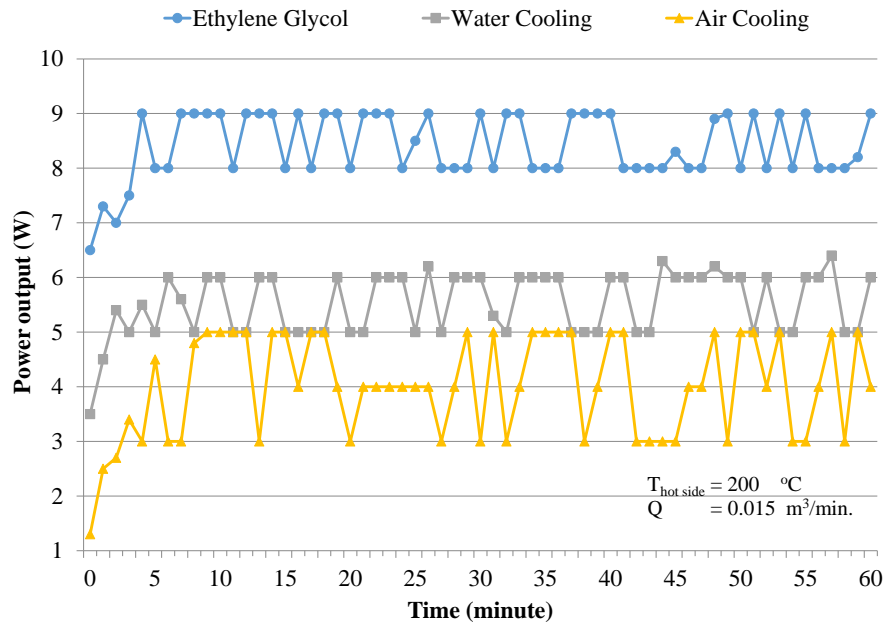

Fig. 7 Effects of cooling technique on the power output of a TE power module 


\section{CONCLUSIONS}

Due to aluminum water cooling block liquid water cooler heat sink limits on the cold side surface of the TE power module with a higher temperature level, the heat transfer characteristics of a liquid flow through the plate-fin heat sink channels in the aluminum cooling block were investigated with ethylene glycol coolant as a working fluid. The effects of fin height for an aluminum plate-fin heat sink, the volumetric flow rate of the ethylene glycol coolant and the heat input condition for the total surface area of the hot side of TE power module on the temperature difference between the hot side surface and cold side surface of the TE power generator were considered. The results obtained from this experiment were compared to water and air cooling methods. It was found that the temperature difference between the hot side surface and cold side surface of the TE power module obtained from the heat sink with a fin height of $8 \mathrm{~mm}$ was higher than that obtained with a fin height of $5 \mathrm{~mm}$ and a higher coolant flow rate, especially with a hot side surface temperature condition at $200{ }^{\circ} \mathrm{C}$. The larger the temperature difference between the hot side surface and cold side surface of the TE power generator, which is based on the Seebeck effect, the more electrical current is produced and more power generated as a result. The TE power module could generate a maximum power output of $8.9 \mathrm{~W}$ per module, which is higher than that of water cooling and air cooling. The results of this study are expected to be one of the interesting alternatives in the design of a cooling system for the TE power generator systems.

\section{ACKNOWLEDGEMENTS}

This work was supported by the research and energy management center, department of physics, faculty of science, Naresuan University, Phitsanulok (Thailand).

\section{REFERENCES}

Champier, D., Bédécarrats, J.P., Kousksou, T., Rivaletto, M., Strub, F., and Pignolet, P., 2011, "Study of a TE (thermoelectric) generator incorporated in a multifunction wood stove," Energy, 36(3), 1518-1526. https://doi.org/10.1016/j.energy.2011.01.012

Cheng, Y.H., and Lin, W.K., 2005, "Geometric optimization of thermoelectric coolers in a confined volume using genetic algorithms," Applied Thermal Engineering, 25(17-18), 2983-2997.

https://doi.org/10.1016/j.applthermaleng.2005.03.007

Fan, Y., Lee, P.S., Jin, L.-W., and Chua, B.W., 2013, “A simulation and experimental study of fluid flow and heat transfer on cylindrical oblique-finned heat sink," International Journal of Heat and Mass Transfer, 61, 62-72.

https://doi.org/10.1016/j.ijheatmasstransfer.2013.01.075

Favarel, C., Bédécarrats, J.P., Kousksou, T., and Champier, D., 2014, "Numerical optimization of the occupancy rate of thermoelectric generators to produce the highest electrical power," Energy, 68:104116. https://doi.org/10.1016/j.energy.2014.02.030

Hsiao, Y.Y., Chang, W.C., and Chen, S,L., 2010, “A mathematic model of thermoelectric module with applications on waste heat recovery from automobile engine," Energy, 35(3),1447-54.

https://doi.org/10.1016/j.energy.2009.11.030
Jang, J.Y., Tsai, Y.C., and Wu, C.W., 2013, "A study of 3-D numerical simulation and comparison with experimental results on turbulent flow of venting flue gas using thermoelectric generator modules and plate fin heat sink," Energy, 53, 270-281. https://doi.org/10.1016/j.energy.2013.03.010

Kim, S.J., Kim, D.K., and Oh, H.H., 2008, "Comparison of fluid flow and thermal characteristics of plate-fin and pin-fin heat sinks subject to a parallel flow," Heat Transfer Engineering, 29(2), 169-177. https://doi.org/10.1080/01457630701686669

Mehrtash, M., and Tari, I., 2013, "A correlation for natural convection heat transfer from inclined plate-finned heat sinks," Applied Thermal Engineering, 51(1-2), 1067-1075. https://doi.org/10.1016/j.applthermaleng.2012.10.043

Pang, S.C., Kalam, M.A., Masjuki, H.H., and Hazrat, M.A., 2012, “A review on air flow and coolant flow circuit in vehicles' cooling system," International Journal of Heat and Mass Transfer, 55(23-24), 6295-6306. https://doi.org/10.1016/j.ijheatmasstransfer.2012.07.002

Peles, Y., Kosar, A., Mishra, C., Kuo, C.J., and Schneider, B., 2005, "Forced convective heat transfer across a pin fin micro heat sink," International Journal of Heat and Mass Transfer, 48 (17), 3615-3627. https://doi.org/10.1016/j.ijheatmasstransfer.2005.03.017

Prajapati, Y.K., Pathak, M., Kaleem Khan, M., 2015, “A comparative study of flow boiling heat transfer in three different configurations of microchannels," International Journal of Heat and Mass Transfer, 85, 711-722, https://doi.org/10.1016/j.ijheatmasstransfer.2015.02.016

Rowe, D.M., and Min, G., 1996, "Design theory of thermoelectric modules for electrical power generation," IEE Proceedings - Science, Measurement and Technology, 143(6), 351-356.

http://dx.doi.org/10.1049/ip-smt:19960714

Rubio-Jimenez, C.A., Kandlikar, A.G., Hernandez-Guerrero, A., 2013, "Performance of online and offset micro pin-fin heat sinks with variable fin density," IEEE Transactions on Components, Packaging and Manufacturing Technology, 3(1), 86-93.

http://dx.doi.org/10.1109/TCPMT.2012.2225143

Siu-Ho, A.M., Qu, W., and Fefferkorn, F.P., 2006, "Pressure drop and heat transfer in a single-phase micro-pin-fin heat sink", IMECE200614777, Proceedings of 2006 ASME International Mechanical Engineering Congress and Exposition, Chicago, IL.

Wang, X.D., Huang, Y.X., Cheng, C.H., Lin, DT.W, and Kang, C.H., 2012, "A three-dimensional numerical modeling of thermoelectric device with consideration of coupling of temperature field and electric potential field," Energy, 47(1), 488-497.

https://doi.org/10.1016/j.energy.2012.09.019

Whelan, B.P., and Robinson, A.J., 2009, "Nozzle geometry effects in liquid jet array impingement," Applied Thermal Engineering, 29(1112), 2211-2221. https://doi.org/10.1016/j.applthermaleng.2008.11.003

Yang, R., Chen, G., Ravi Kumar, A., Jeffrey Snyder, G., and JeanPierre Fleurial, 2005, "Transient cooling of thermoelectric cooler and its application in microdevices," Energy Conversion and Management, 46(9-10), 1407-1421. https://doi.org/10.1016/j.enconman.2004.07.004

Zhao, C.Y., and Lu, T.J., 2002, "Analysis of microchannel heat sink for electronics cooling," International Journal of Heat and Mass Transfer, 45(24), 4857-4869. https://doi.org/10.1016/S0017-9310(02)00180-1. 